\title{
A (in)visibilidade dos acontecimentos e a lógica do condomínio na sociedade brasileira contemporânea ${ }^{1}$
}

\section{(In) visibility of events and the condo logic in contemporary Brazilian society}

Paula Guimarães Simões²

1 Uma primeira versão do artigo foi apresentada no seminário Polarizações, promovido pelo Grupo de Pesquisa Mídia e Narrativa, da Pontifícia Universidade Católica de Minas Gerais (PUC Minas), em Belo Horizonte (03-05/11/2015). 
O objetivo deste texto é refletir sobre o cenário de polarizações que marca o contexto brasileiro a partir do cruzamento entre dois acontecimentos ocorridos em agosto de 2015: a chacina que vitimou 18 pessoas em Osasco e Barueri, no dia 13, e as manifestações contra o governo Dilma, no dia 16. A associação entre os dois acontecimentos trouxe à tona algumas polarizações que constituem a cena pública contemporânea: entre os pró e os contra o governo do PT, entre centro e periferia, entre ricos e pobres. A análise revela traços da "lógica do condomínio" (DUNKER, 2015) que caracteriza nossa sociedade: uma forma de vida marcada pela segregação, em que "muros" impedem o diálogo e a compreensão entre os diferentes - o que é central na construção de uma sociedade democrática.

\section{Palavras-chave}

Morte, acontecimento, polarizações, lógica do condomínio. 
This paper aims at discussing the polarizations scenario which marks the Brazilian context from the crossing between two events that occurred in August 2015: the slaughter that killed 18 people in Osasco and Barueri (São Paulo), on the $13^{\text {th }}$, and the manifestations against Dilma Rousseff government, on the $16^{\text {th }}$. The association between both events brought some polarizations which constitute the contemporary public scene: between pro and antigovernment people, between center and periphery, between rich and poor people. The analysis reveals features of a kind of "condo logic" (DUNKER, 2015) that characterize our society: a life form marked by segregation, in which "walls" prevent the dialogue and the comprehension between different people - what is central in the building of a democratic society.

\section{Keywords}

Death, event, polarizations, condo logic. 


\section{Introdução}

A temática discutida no presente texto parte da pesquisa "Da morte à biografia: acontecimentos, celebridades e vida social"3. Nela, analisamos a morte de figuras públicas como o político Eduardo Campos, o líder sul-africano Nelson Mandela, o jogador de futebol Sócrates, além dos atores Robin Williams, José Wilker e Walmor Chagas. De modo geral, o que percebemos ao analisar a morte de tais personalidades?

Em primeiro lugar, tais mortes de figuras públicas se configuram como um acontecimento que recebe ampla visibilidade midiática (com diferentes dimensões em cada caso). Em segundo, como outros acontecimentos, tais mortes têm um "poder hermenêutico" (QUÉRÉ, 2005), ou seja, podem revelar traços do contexto em que se inscrevem ou iluminar certos campos problemáticos (a morte de Robin Williamns, por exemplo, trouxe à tona a questão da depressão e do suicídio, enquanto a de Sócrates problematizou o alcoolismo). Em segundo lugar, elas afetam as pessoas de diferentes maneiras, dependendo: a) do tipo de morte (um suicídio, um desastre de avião ou uma morte por idade, que segue o curso natural da vida, afetam diferentemente os sujeitos); b) da biografia do morto (sua trajetória profissional e pessoal, bem como os valores agregados à sua imagem, sensibiliza o público diante desse acontecimento derradeiro de uma vida).

Ao investigar essas mortes, começamos a refletir sobre outras que não recebem o mesmo tratamento pela mídia e, muitas vezes, não sensibilizam tanto a sociedade: a dos anônimos. Quando a morte destes pode ganhar o espaço de visibilidade pública? Segundo Antunes, é quando "a morte aparece pelo aspecto do trágico, das tragédias pessoais. É quando a morte de pessoas comuns adquire alguma visibilidade pública" (ANTUNES, 2012, p. 62). Ou, podemos acrescentar, quando se trata de um crime que envolve uma figura de destaque, como ocorreu no assassinato de Eliza Samúdio e o envolvimento do então goleiro do Flamengo, Bruno Fernandes - acontecimento analisado em um dos recortes da pesquisa4. Ou, ainda, quando são muitos os envolvidos em uma tragédia (como um desastre aéreo, um acidente com muitas vítimas). Como destaca Antunes, "os números são uma poderosa maneira de reportar a morte" (2012, p. 58). De modo geral, as mortes dos anônimos são noticiadas e logo caem no esquecimento, suplantadas por outras notícias diariamente (o caso Eliza Samúdio é uma exceção nesse contexto).

É para esse tipo de morte - dos anônimos - que gostaríamos de voltar nosso olhar nesta reflexão e, mais especificamente, para um acontecimento que

3 Agradeço o apoio do CNPq, da FAPEMIG e da PRPq/UFMG ao desenvolvimento desta pesquisa. 
chamou nossa atenção ao pensar sobre a relação entre a morte de célebres e anônimos, no contexto brasileiro contemporâneo: a chacina ocorrida no dia 13 de agosto de 2015 que vitimou 19 pessoas em Osasco e Barueri. Discutiremos esse acontecimento e algumas de suas repercussões que o conectaram a outro acontecimento no mesmo mês: as manifestações contra o governo Dilma, no dia 16. O objetivo é apreender o "poder de revelação desse acontecimento", como sugere Hannah Arendt, pois ele pode revelar uma "inesgotável paisagem de ações, sofrimentos e novas possibilidades" (ARENDT, 2008, p. 343). Nesse sentido, buscamos compreender o que ele pode elucidar da sociedade em que vivemos - e das polarizações que a constituem no contexto contemporâneo.

Assim, o texto está dividido em duas partes: na primeira, apresentamos sucintamente os dois acontecimentos e apreendemos alguns de seus cruzamentos em três espaços: 1) um texto da jornalista e escritora Eliane Brum; 2) um relato do fotojornalista Matheus José Maria; 3) uma charge da cartunista Laerte. Certamente, os acontecimentos se cruzaram em outros textos disponíveis, e o recorte assim construído apresenta limitações. Entretanto, acreditamos que eles ajudam a refletir sobre o cruzamento entre os dois acontecimentos aqui em análise e as polarizações, que são o tema deste artigo. Na segunda parte, para concluir, apontamos dois eixos configuradores desse contexto brasileiro contemporâneo que podem ser apreendidos a partir do material analisado.

\section{A chacina: o que aconteceu?}

Era noite de quinta-feira, 20h30. A chacina começou com dez pessoas baleadas por indivíduos encapuzados em um bar em Osasco. Outros tiros seriam dados em diferentes lugares da região, dirigidos a homens, mulheres e até crianças. A 19a vítima fatal dessa chacina foi contabilizada no fim do mês de agosto: uma menina de 15 anos, que não resistiu a uma infecção abdominal resultante dos ferimentos (ALESSI, 27/08/2015). As investigações não foram concluídas, mas apontam que a chacina seria uma retaliação de policiais militares em virtude da morte de um colega dias antes na mesma região.

\section{As manifestações na Avenida Paulista}

No domingo, 16 de agosto, milhares de pessoas foram para a Avenida Paulista, em São Paulo, protestar contra o Partido dos Trabalhadores (PT) e o governo Dilma Rousseff. Segundo o Datafolha, foi 135 mil o número de manifestantes que reivindicavam a queda da presidenta eleita (CARTA CAPITAL, s./d.). O ato deu sequência a outros protestos que aconteceram não apenas em São Paulo, mas em outras cidades do Brasil, e que haviam começado a surgir desde março de 2015. 


\section{Como esses acontecimentos se cruzaram?}

Uma chacina. Uma manifestação contra o governo. Como dois acontecimentos tão distintos se cruzaram e como eles podem iluminar esse cenário de polarizações que vem marcando nossa sociedade? Talvez eles tenham se entrelaçado em outros discursos, mas vou me limitar aqui a três espaços que nos ajudam a refletir sobre a questão das polarizações.

\section{Texto de Eliane Brum}

Em um instigante texto sobre a chacina, a escritora e jornalista Eliane Brum questiona em seu título: "Quando a periferia será o lugar certo na hora certa?". Brum relata que o comentário "Estava no lugar errado e na hora errada" foi o mais frequente dos familiares dos mortos e feridos na maior chacina ocorrida em São Paulo em 2015. Ela lembra que essa "expressão dá conta de uma máxima: 'na periferia há preto ladrão, branco ladrão e aquele que está no lugar errado e na hora errada'. A frase também culpa, ainda que indiretamente, aquele que morre". Assim, para escapar do que seria o "lugar errado, na hora errada", as pessoas da periferia se trancam em casa. "Cada vez mais acuados, aqueles que não querem morrer se resignam a desistir do espaço público", escreve a jornalista.

É a vida dos escravos, sonhada por seus senhores: de casa pro ônibus lotado, do ônibus lotado pro trabalho, do trabalho pro ônibus lotado, do ônibus lotado pra casa. Gente pobre não precisa de lazer ou o lazer é ver TV em casa, preferencialmente programas em que apresentadores, alguns deles com ambições eleitorais, criminalizam pobres e ofertam a imagem de seus corpos no altar midiático. Quem frequenta bar, sabe que pode morrer, é este o recado. Como na noite de 13 de agosto, como em tantas outras noites. Ser encurralado por homens encapuzados e executado a tiros nunca é a possibilidade no lugar certo e na hora certa (BRUM, 19/08/2015).

No texto de Eliane Brum, apreendemos um dos traços dessa forma de vida que Christian Dunker (2015) nomeia como a "lógica do condomínio" na sociedade brasileira. Em seu recente livro Mal-estar, sofrimento e sintoma, o autor usa essa metáfora do condomínio para pensar a segregação entre muros que se constrói a partir do encolhimento do espaço público e que busca afastar o risco e a indeterminação de uma sociedade marcada pela hiperindividualização. No condomínio da periferia, assim, os muros encerram aqueles que não querem estar "no lugar errado, na hora errada". 
Oposto a esse "condomínio" da periferia, podemos situar um outro que se constrói em absoluto contraste: formado por aqueles que ignoram o que se passa no condomínio ao lado ou que, mesmo que tomem conhecimento da violência de uma chacina como essa, aparentam não se importar com a tragédia. Membros desse outro grupo podem ser identificados entre os manifestantes daquele 16 de agosto, na Avenida Paulista, como relata Eliane Brum:

Na larga Paulista, a avenida-símbolo da pujança de São Paulo, ocupada por cerca de 135.000 manifestantes, a maioria deles homens, autodeclarados brancos e com curso superior, segundo pesquisa do Datafolha, era como se nada tivesse acontecido do outro lado do rio, as pontes dinamitadas também por mais esse gesto. Era como se não existissem 18 corpos furados à bala e chorados por dezenas nos cemitérios das periferias da Grande São Paulo (BRUM, 19/08/2015).

Indiferentes à tragédia de poucos dias antes, milhares de pessoas se vestiram de verde e amarelo para protestar contra a corrupção, o PT e o governo de Dilma Rousseff. Ao lado de policiais militares, tiraram selfies que nada diziam do provável envolvimento de policiais na chacina ignorada naquela manifestação. Como destaca Brum:

As pessoas "de bem" que se manifestavam pelo impeachment da presidente Dilma Rousseff reeditavam sua admiração e confiança em uma das polícias que mais mata no mundo. Apertavam a mão de policiais, davam parabéns pelo bom trabalho. Depois, tiravam selfies. Abraçadas aos PMs, fazendo sinal de positivo (BRUM, 19/08/2015).

O relato de Eliane Brum e a aproximação entre os dois acontecimentos - a chacina e a manifestação - nos fazem lembrar uma pergunta colocada por Hans Joas (2012) em sua genealogia dos direitos humanos: como e quando uma instituição (como a escravidão, na reflexão do autor) pode se tornar objeto de nossa indignação moral? A chacina não sensibilizou a sociedade a ponto de indignar amplamente as pessoas e impulsionar grandes protestos contra a violência na periferia ou a violência dos policiais. Inscrevendo-se nesse campo problemático da 
violência, esse acontecimento revela o estado de terror que reina nas periferias de São Paulo e outras capitais do país, como destaca Brum: "O 13 de agosto prova, mais uma vez, que as periferias paulistas vivem sob estado de terror, provocado por uma guerra não declarada. Nela, tombam os mais pobres, a maioria deles negros" (BRUM, 19/08/2015).

\section{No relato do fotojornalista Matheus José Maria}

O segundo espaço em que pudemos perceber o cruzamento entre os dois acontecimentos é um relato escrito pelo fotojornalista Matheus José Maria, em 17 de agosto de 2015, que narra esse entrecruzamento na própria manifestação da Avenida Paulista. De acordo com o texto, um grupo formado por membros dos Jornalistas Livres realizou um protesto contra a violência na periferia ocorrida no mesmo fim de semana: uma atriz, ensanguentada de ketchup, encenava a própria morte enquanto outra atriz chorava em prantos sobre seu corpo.

Diante da cena, o que os manifestantes fizeram? Alguém usou tinta verde e amarela para escrever em sua testa (e, possivelmente, para fazer contraste com todo o vermelho que sujava suas roupas); outro manifestante atirou tintas em sua direção; outro, ainda, colou um adesivo em sua testa. A atriz, relata o fotógrafo, "como uma boa morta, não se mexia, não reclamava, apenas ficava ali inerte, cumprindo o seu papel e jogando na cara deles uma realidade que praticamente todos ali faziam questão de ignorar". No fim da intervenção, a atriz se levantou e parecia ignorar os gritos de bandida, vagabunda, ladrão (sic), segundo o mesmo relato.

Matheus José Maria tentou conversar com esses manifestantes e nos chama a atenção, sobretudo, o posicionamento da senhora das tintas. Conforme o fotógrafo,

A dama da paulista disse que fez isso porque era uma provocação dos petistas, quando retruquei dizendo que aquele ato não tinha relação com o PT e era uma crítica aos assassinatos do final de semana. Com toda a educação do mundo (e arrogância de um burguês no sentido literal da palavra) ela me disse que "Ali não era lugar pra fazer isso. Se quisessem protestar que fossem fazer isso lá em Osasco e não ali na Paulista". Com um profundo pesar (pelo tipo de ser humano que ela era) perguntei se a violência na periferia não era uma pauta que merecia ser levada às ruas, mas ela disse que "não, coisa da periferia tem que ser resolvida na periferia" e após proferir essa frase abundante em bondade, democracia e justiça (vale lembrar que virava e mexia se ouvia nos trio elétricos alguém dizendo que eles não estavam lá por se preocuparem com seus próprios umbigos, 
mas sim por querer o melhor para o país todo. Aham... senta lá Cláudia!) ela encerrou o assunto dizendo "Você não concorda comigo e eu não concordo com você, então não tem porque conversarmos". Não sei se só para mim isso soou como você está comigo ou está contra mim (MARIA, 17/08/2015).

É um posicionamento de uma manifestante entre os milhares que foram às ruas naquele domingo de agosto, narrado por um jornalista, entre os muitos que lá também estiveram. Sem pretensão de generalizações, acreditamos que é possível apreender nesse relato de Matheus José Maria alguns elementos configuradores desse cenário de polarizações que estamos discutindo aqui (e da lógica do condomínio apontada anteriormente).

O protesto realizado pelos Jornalistas Livres não conseguiu sensibilizar aquelas pessoas, não impulsionou a indignação delas diante das mortes em Osasco e Barueri, diante da violência na periferia contra a qual a intervenção protestava. Ao contrário, o protesto parece ter impulsionado outra indignação: contra a invasão daquele espaço (a Paulista) pela periferia ou por pessoas que falavam em nome dela; contra a ocupação daquela manifestação por outras vozes que não estavam ali para levantar as mesmas pautas: o lugar da periferia é na periferia. Além disso, o relato exibe a dificuldade ou mesmo a impossibilidade do diálogo entre os que pensam de forma diferente - ou os membros de "condomínios" distintos. Isso é muito evidente na fala da senhora da Paulista: "Você não concorda comigo e eu não concordo com você, então não tem por que conversarmos".

\section{Na charge de Laerte ${ }^{5}$}

Um terceiro e último espaço em que esses dois acontecimentos se cruzaram que gostaríamos de destacar aqui é uma charge de Laerte, publicada pela Folha de S. Paulo no dia 18 de agosto. Nela, a cartunista associa os dois acontecimentos, a chacina e as manifestações da Paulista, em que diferentes indivíduos tiraram selfies com os policiais: dois manifestantes estampando camisetas "Fora Dilma" abraçam-se a sujeitos encapuzados e armados saindo de uma porta em que o sangue jorra pelo chão.

Segundo a ombudsman da Folha, Vera Guimarães Martins, "nestes tempos beligerantes" em que vivemos, nenhuma charge "havia provocado até agora tanta reação" (MARTINS, 23/08/2015) como esta. A charge gerou uma versão modificada em que manifestantes pró-PT seriam coniventes com a corrupção. 
$\mathrm{Na}$ charge e na contra-charge, percebemos a oposição que vem marcando o cenário político desde as eleições entre os pró e os contra Dilma e o governo do PT. Em cartas de leitores reproduzidas pela própria ombudsman e publicadas no Painel do Leitor, sujeitos manifestam sua indignação com a articulação realizada por Laerte na charge:

A charge de Laerte ("Opinião", 18/8) é execrável, de extremo mau gosto. O cartunista demonstra que já condenou a PM pela chacina, antes mesmo da investigação concluída, e que generalizou, ao sugerir que todo policial militar é criminoso. Além disso, insinua que os manifestantes anti-PT, cansados de sofrer com as monstruosidades políticas, econômicas e administrativas do atual (des)governo, são a favor da chacina. Deplorável! Leonardo Basilio Lourenço, historiador (São Bernardo do Campo, SP)

Registro a minha repulsa à charge de Laerte, que há muito cruzou a fronteira entre o humor crítico e a mais vulgar militância.

Alexandre A. Rocha (Brasília, DF)

Qual foi a intenção de Laerte? Associar protestos legítimos contra a corrupção e a incompetência do governo do PT a crimes? Crimes são fatos contra os quais a maioria significativa da população se manifesta neste momento de "Fora, Dilma", desde o estelionato eleitoral, destruição das condições de desenvolvimento econômico e social até a institucionalização da corrupção.

Marco Milani, professor universitário (São Paulo, SP)

O que esperar de alguém que, como cartunista já foi bom, mas no domingo (16) vai ao churrasquinho da CUT em frente ao Instituto Lula e na terça (18) publica aquela charge infeliz, tentando ligar os manifestantes de domingo com a tragédia de Osasco e Barueri? Senhor Laerte, peça desculpas às famílias das vítimas. Não politize a desgraça.

Hélio Araújo Cardoso (São Carlos, SP)

Houve, porém, duas manifestações selecionadas para publicação pelo jornal que destoaram da indignação mostrada anteriormente: 
Excelente a charge de Laerte. Mostra a alienação de grupos que se apresentam nas passeatas como defensores de um Brasil com menos corrupção, focando, para isso, quase exclusivamente o "Fora, Dilma" e o "Fora, PT".

Maria Elvira Nóbrega Zelante (Marília, SP)

Creio que a charge do Laerte ("Opinião", 18/8) chame a atenção para o fato de que, para os paulistanos, todos os problemas se concentram na esfera federal. Não há uma só queixa contra o governo do Estado. Mesmo diante da crise na segurança pública, casos de corrupção etc.

Carlos Alberto dos Santos (São Paulo, SP).

$\mathrm{Na}$ charge, na contra-charge e nessa breve repercussão lembrada aqui, podemos ver claramente a polarização que vem marcando o contexto brasileiro contemporâneo entre aqueles que reconhecem o governo legitimamente eleito de Dilma, por um lado, e aqueles que veem tal governo como o institucionalizador da corrupção, por outro. Nesse pequeno universo de discursos, chama a atenção que a própria chacina e a violência que a gerou quase desapareçam. A indignação tem seu objeto aqui na charge, na militância política de Laerte e no governo de Dilma; a polícia militar e suas ações não se configuram como tal. É curioso notar que há uma reivindicação de que a PM não seja condenada pela chacina antes de a investigação ser concluída - mas o mesmo argumento não vale para a destituição de Dilma de seu mandato.

\section{Como compreender?}

Nossa reflexão foi iniciada aqui com uma tentativa de compreender o cruzamento entre dois acontecimentos marcantes no cenário brasileiro contemporâneo, sem qualquer pretensão de chegar a generalizações ou esgotar os sentidos que tais fenômenos poderiam indicar. Ao revisitar três espaços em que a chacina e a manifestação contra o governo foram associadas, procuramos evidenciar alguns traços da sociedade brasileira que podem ser percebidos a partir dos discursos explorados nessa breve análise. Nesse sentido, para concluir, procuramos apontar dois eixos configuradores de nosso contexto que dizem do "poder de revelação", conforme Arendt, ou do "poder hermenêutico" (QUÉRÉ, 2005) desses acontecimentos. 
Em primeiro lugar, esses acontecimentos e seus cruzamentos evidenciam a "lógica do condomínio" que constitui a sociedade brasileira contemporânea, conforme a reflexão do psicanalista Christian Dunker (2015). Como explicitado anteriormente, trata-se de uma forma de vida construída a partir da segregação entre grupos que se isolam entre muros: a ideia do "cada um no seu quadrado". É uma forma de vida marcada pela individualização excessiva, em que cada grupo (ou cada indivíduo dentro dele) se preocupa com seu próprio universo, insensível e/ou indiferente ao condomínio ao lado.

Percebemos essa lógica na segregação entre a periferia e o centro marcada em posicionamentos como o da senhora das tintas durante a manifestação na avenida Paulista, em São Paulo, que reitera a marcação desses espaços: "coisa da periferia tem que ser resolvida na periferia". É uma lógica que evidencia um traço constituidor da sociedade brasileira, apesar dos inúmeros avanços conquistados nos últimos anos: a desigualdade social. Como destacam Lilia Schwarcz e Heloisa Starling no recente Brasil: uma biografia, apesar do crescimento espantoso que faz com que o país se comporte como a sétima potência mundial, ele "segue sendo campeão em desigualdade social e pratica um racismo silencioso mas igualmente perverso" (SCHWARCZ; STARLING, 2015, p. 14).

A mesma lógica do isolamento de grupos pode ser percebida na polarização entre os pró e os contra o governo do PT. Como explica Dunker em sua análise dessas polarizações, conforme entrevista concedida à Folha de S. Paulo em 21 de março de 2015, "As partes envolvidas traduzem o conflito em termos de dois condomínios - o vermelho e o azul, sem entender que existe um espaço em comum chamado Brasil" (DUNKER apud LUCENA, 21/03/2015). O próprio sentido do "comum" parece se esvaziar aos poucos, quando vemos em que direção a indignação dos sujeitos avança.

Em segundo lugar, chama a atenção a impossibilidade do diálogo entre sujeitos pertencentes a "condomínios" distintos: periferia e centro, pobres e ricos, pró e contra governo. Tal impossibilidade pode ser apreendida na indiferença de muitos diante da tragédia de Osasco e Barueri: como se o que acontece na periferia não tivesse lugar fora dela, nem mesmo as vozes que falam em nome dela. Isso pode ser apreendido, ainda, em frases como a da mesma senhora da Paulista: "Você não concorda comigo e eu não concordo com você, então não tem porque conversarmos". Ao mesmo tempo em que há uma valorização da liberdade de falar e de se expressar (em um protesto pacífico e democrático, como reivindicaram muitos manifestantes naquele 16 de agosto de 2015), há uma indisposição na escuta aos posicionamentos dos outros - o que dificulta a própria construção de uma sociedade democrática. 
Como bem evidencia Mendonça (2013), ao retomar contribuições de pensadores pragmatistas como J. Dewey e G. H. Mead, a democracia se constrói na garantia do exercício desse duplo direito: de falar e de ser ouvido. É o diálogo - ou a discussão pública em torno de questões que dizem respeito ao bem comum - o grande alicerce na construção de uma sociedade democrática. Nesse sentido, a violência na periferia, o papel e as ações da PM, bem como a segregação de espaços e grupos em nossa sociedade devem ser alçados ao centro do debate para que os problemas públicos possam ser tematizados, discutidos e amplamente enfrentados. 


\section{Referências}

ALESSI, G. "Adolescente de 15 anos é a 19a vítima fatal da chacina de Osasco". El País. 27 de agosto de 2015. Disponível em: http://brasil.elpais.com/ brasil/2015/08/27/politica/1440693639_365701.html. Acesso em: 30 mai. 2016.

ANTUNES, E. "Noticias depois da morte: visibilidades e ausências no jornalismo". In: MAROCCO, B.; BERGE, C.; HENN, R. (Org.). Jornalismo e acontecimento diante da morte volume 3. $1^{\mathrm{a}}$ ed. Florianópolis: Insular, 2012, pp. 49-69.

ARENDT, H. "Compreensão e Política". In: Compreender: formação, exílio e totalitarismo. São Paulo: Companhia das Letras; Belo Horizonte: Editora UFMG, 2008.

BRUM, E. "Quando a periferia será o lugar certo, na hora certa?". El País. de agosto de 2015. Disponível em: http://brasil.elpais.com/brasil/2015/08/17/ opinion/1439819813_934995.html. Acesso em: 30 mai. 2016.

CARTA CAPITAL. "Manifestações no dia 16/8". Carta Capital. s./d. Disponível em: http://www.cartacapital.com.br/manifestacoes-no-dia-16-8>. Acesso em: 30 mai. 2016.

DUNKER, C. Mal-estar, sofrimento e sintoma. São Paulo: Boitempo, 2015.

JOAS, H. A sacralidade da pessoa: nova genealogia dos direitos humanos. São Paulo: UNESP, 2012.

LUCENA, E. "'Lógica de condomínio' traz cisão ao país, diz psicanalista". Folha de S. Paulo. 21 mar. 2015. Disponível em: http://www1.folha.uol.com.br/ ilustrada/2015/03/1605857-logica-de-condominio-traz-cisao-ao-pais-dizpsicanalista.shtml. Acesso em: 30 mai. 2016.

MARIA, M. J. "O dia em que me tornaram petista". Medium. 17/08/2015. Disponível em: https://medium.com/@matheusjosemaria/o-dia-em-que-me-tornarampetista-e5faa2b4e91\#.sw78zbi74. Acesso em: 30 mai. 2016.

MARTINS, V. G. "A vida em preto e branco". Folha de S. Paulo, 23 de agosto de 2015. Disponível em: http://www1.folha.uol.com.br/colunas/veraguimaraesmarti ns/2015/08/1672317-a-vida-em-preto-e-branco.shtml. Acesso em: 30 mai. 2016.

MENDONÇA, R. F. "A liberdade de expressão em uma chave não dualista: as contribuições de John Dewey". In: LIMA, V.; GUIMARÃES, J. (org.). Liberdade de expressão: as várias faces de um desafio. São Paulo: Paulus, 2013, v. 1, p. 41-63. 
QUÉRÉ, L. "Entre o facto e o sentido: a dualidade do acontecimento". Trajectos. Revista de Comunicação, Cultura e Educação, n. 6. Lisboa, 2005, p. 59-75.

SCHWARCZ, L. M.; STARLING, H. M. Brasil: uma biografia. São Paulo: Companhia das Letras, 2015.

submetido em: 14 mar. 2016 | aprovado em: 04 mai. 2016 